\title{
TRANSFORMAÇÕES RECENTES DO AGRONEGÓCIO MINEIRO: UMA ANÁLISE DE INDICADORES DE COMÉRCIO EXTERIOR NO PERÍODO DE 1996 A $2006^{12}$
}

\author{
Luiz Eduardo de Vasconcelos Rocha ${ }^{3}$ \\ Wilson Teixeira de Andrade Leite ${ }^{4}$
}

Resumo - O propósito deste trabalho foi analisar a especialização e a competitividade da agroindústria do estado de Minas Gerais e sua contribuição para a expansão das exportações brasileiras. Para isso, foram utilizados alguns indicadores baseados nos fluxos comerciais, os quais permitem identificar a tendência da especialização no mercado internacional. A análise da evolução da estrutura do comércio exterior e das vantagens competitivas demonstrou a diversificação do agronegócio mineiro, iniciada a partir de 1999 com o aumento de capítulos identificados como ponto forte na economia. O Estado manteve a competitividade dos setores tradicionais, como café e madeira, e ainda diversificou a sua produção para outros setores com maior valor agregado. Entretanto, o indicador de competitividade para Minas Gerais foi neutro, isso porque o setor apresentou desvantagem competitiva revelada, que vem sendo gradativamente revertida. Se esse segmento mantiver tal tendência, não há dúvidas de que, em futuro próximo, o agronegócio será qualificado como ponto forte da economia mineira.

Palavras-chave: vantagem competitiva, especialização, agronegócio mineiro.

Recebido em 13/07/2007. Aceito em: 28/09/2007.

2 Os autores agradecem as sugestões de dois pareceristas anônimos da Revista. Os possíveis erros remanescentes são de responsabilidade exclusiva dos autores.

3 Professor da Universidade Federal de São João del Rei - UFSJ. E-mail: levrocha@ufsj.edu.br

4 Pós-graduando em Economia e Gestão do Agronegócio - UFSJ. E-mail: wilson.04@mgconecta.com.br 


\section{Introdução}

Atualmente, o agronegócio tem importância fundamental para diversos setores da economia brasileira. Na geração de emprego, responde por $35 \%$ da população economicamente ativa; na geração de riquezas, contribui com, aproximadamente, $31 \%$ do produto interno bruto do país; e, nas contas externas, é responsável por grande parte do superávit da balança comercial, com participação de $42 \%$ das exportações brasileiras.

Segundo Jank et al. (2005), o atual estágio de desenvolvimento do agronegócio brasileiro, que coloca o país entre as nações mais competitivas do mundo na produção de commodities agroindustriais, teve o seu momento de inflexão a partir de 2000, com a desvalorização do real e com o aumento da demanda no mercado internacional. Desde então até 2006, a produção de grãos passou de 57,8 milhões para 126 milhões de toneladas e as exportações, de 18,1 bilhões para 46,2 bilhões, apresentando taxa de crescimento anual de $19,7 \%$.

Esse desempenho notável de um lado contou com a combinação de fatores que, desde a década de 70, deu suporte ao setor, como investimentos em pesquisa e tecnologia, aumento da produtividade, redução na intervenção do governo com a desregulamentação dos mercados, abertura comercial e estabilização da economia com o Plano Real. Deve-se ressaltar, no entanto, que a mudança de postura do setor em relação ao mercado externo também deu a sua contribuição. Se, antes, a atividade exportadora era encarada sob a ótica do escoamento de excedentes, atualmente ela é vista como complemento ao mercado interno, em que ganhar mercado passou a ser uma obsessão. Nesse sentido, o crescimento das exportações brasileiras se deve, em parte, à capacidade que o setor vem demonstrando em defender seus interesses nas negociações nos fóruns internacionais. A perspectiva futura do setor agroindustrial brasileiro depende do sucesso dessas negociações na redução das barreiras e proteções tarifárias, que incidem sobre $90 \%$ de tudo que o setor exporta 5 .

Atualmente, o Brasil está envolvido simultaneamente em três rodadas de negociações, quais sejam, Área de Livre Comércio das Américas (ALCA), acordo bilateral União Européia-Mercosul e Organização Mundial do Comércio (OMC). 
Nesse contexto, o propósito do trabalho é analisar a especialização e a competitividade da agroindústria do estado de Minas Gerais e sua contribuição na expansão das exportações brasileiras, no período de 1996 a 2006. Para isso, utilizaram-se alguns indicadores baseados nos fluxos comerciais, os quais permitem identificar a tendência da especialização do agronegócio mineiro no mercado internacional. Além dessa introdução, o trabalho foi composto de mais três seções. Na próxima, descrevem-se brevemente as metodologias utilizadas para identificar a especialização e competitividade das exportações, a composição do setor agroindustrial e as fontes de dados; em seguida, apresentam-se a estrutura, o destino das exportações do Estado e os resultados dos indicadores; e, no final, são comentadas as conclusões.

\section{Metodologia}

Nesta seção, inicialmente foram descritos os indicadores propostos por Balassa (1965) e, posteriormente, por Lafay (1990), para mensurar a especialização da economia regional no mercado internacional. Com o processo de globalização e a abertura brasileira, iniciados no final da década de 80, vários autores, como Fernandes e Vieira (2000), Maia (2005) e Hidalgo (1998), utilizaram esses indicadores para mensurar a dinâmica da especialização da economia brasileira. Posteriormente, foram descritos o conceito e a composição do agronegócio e, também, a fonte dos dados.

\subsection{Vantagem comparativa revelada}

Para mensuração da vantagem comparativa revelada (VCR) não é necessária a ocorrência do comércio bilateral, na medida em que o indicador é calculado a partir dos preços relativos dos bens (Fernandes; Vieira, 2000). Pelo índice de VCR calcula-se a participação das exportações de dado produto de determinada região, em relação à participação dessa região, no total das exportações do país. Assim, o 
indicador para uma região j, em um grupo de produtos i, pode ser definido pela seguinte forma:

$$
V C R_{i j}=\frac{X_{i j} / X_{i z}}{X_{j} / X_{z}},
$$

em que $X_{i j}$ é o valor das exportações do produto i, na região $\mathrm{j} ; X_{i z}$, valor das exportações do produto i, na zona de referência $\mathrm{z} ; X_{j}$, valor total das exportações da região $\mathrm{j}$; finalmente, $X_{z}$, valor total das exportações da zona de referência $z$.

Quanto maior for o volume exportado de determinado produto por uma região, com relação ao volume total exportado desse mesmo produto, maior será a vantagem comparativa na produção desse bem. Para $V C R_{i j}$ maior que a unidade, admite-se que o produto i apresente vantagem comparativa revelada; para valores menores que a unidade, o produto $\mathrm{i}$ apresenta desvantagem comparativa revelada.

\subsection{Contribuição para o saldo comercial}

O índice de contribuição para o saldo comercial (ICSC), definido por Lafay (1990), consiste na comparação do saldo comercial observado de cada produto, ou grupo de produtos, com o saldo comercial teórico desse mesmo produto. O indicador ICSC de um produto ou de grupo de produtos $\mathrm{i}$, em uma região j, pode ser apresentado da seguinte forma:

$$
\operatorname{ICSC}_{I J}=\frac{100}{(X+M) / 2} \cdot\left[\left(X_{i}-M_{i}\right)-(X-M) \cdot \frac{\left(X_{i}+M_{i}\right)}{(X+M)}\right],
$$


em que $X_{i}$ representa as exportações do bem i e; $M_{i}$, importações do bem i. O primeiro termo entre colchetes representa a balança comercial observada do produto i, enquanto o segundo corresponde à balança comercial teórica do produto i. Quando $I C S C_{i j}$ tiver valor positivo, considera-se que o produto i apresentará vantagem comparativa revelada; para valores negativos, o produto exibirá desvantagem.

\subsection{Taxa de cobertura}

Segundo Gutman e Miotti (1996), o cálculo da taxa de cobertura (TC) permite determinar os pontos fortes e fracos na especialização de uma economia regional. A taxa de cobertura do produto i é definida da seguinte forma:

$$
T C_{i}=\frac{X_{i}}{M_{i}}
$$

em que $X_{i}$ são as exportações e $M_{i}$, importações do produto i ou de grupo de produtos de dada região.

Os produtos que apresentam, simultaneamente, vantagem comparativa revelada (VCR) e taxa de cobertura (TC) superior à unidade são considerados pontos fortes da economia, enquanto os com desvantagem comparativa revelada e, simultaneamente, com taxa de cobertura inferior à unidade são considerados pontos fracos. No caso em que se observarem vantagem comparativa e taxa de cobertura inferior à unidade ou vive-versa, o produto será considerado ponto neutro. A identificação desses pontos fortes e fracos permite determinar os produtos com melhores oportunidades de inserção comercial. 


\subsection{Composição do agronegócio e fonte de dados}

Segundo Bacha (2004), o agronegócio ou complexo agroindustrial (CAI) representa o conjunto de atividades realizadas pela agropecuária e pelos setores a ela vinculados, ou seja, trata-se do "conjunto formado pela sucessão de atividades vinculadas à produção e à transformação dos produtos agropecuários"

Dada a amplitude do conceito, análises e instituições que abordam o cômputo de estatística da balança comercial do agronegócio adotam diferentes metodologias para a composição do setor. A Organização Mundial do Comércio (OMC), a partir do sistema harmonizado de mercadorias (SHM), apresenta uma composição mais restrita para o setor. Em contraposição, o Ministério da Agricultura, Pecuária e Abastecimento (MAPA) utiliza uma definição mais ampla, incluindo uma gama maior de produtos da Nomenclatura Comum do Mercosul (NCM). Neste trabalho, adotou-se uma definição intermediária à da $\mathrm{OMC}$ e à do MAPA. O conceito inclui todos os produtos da NCM que pertencem à cadeia produtiva de uma matéria-prima agropecuária, independentemente do nível de agregação, sendo constituído pelos seguintes capítulos: 1 a $24,41,42,44,45,47,48$ e 50 a 53.

Os índices que irão mensurar a dinâmica da especialização do agronegócio mineiro, calculados a partir das informações das exportações e importações mineiras e brasileiras para os 34 capítulos que compõem o agronegócio, segundo a definição adotada neste trabalho, utilizarão dados do comércio exterior disponibilizados pela Secretaria de Comércio Exterior do Ministério da Indústria, Comércio e Turismo (SECEX/MICT), disponíveis por meio do sistema Análise das Informações de Comércio Exterior (ALICE). As informações são agregadas em 22 seções, que, por sua vez, são compostas de 99 capítulos, que se subdividem em produtos com especificações de até oito dígitos.

6 Esse conceito e as suas diferenciações são apresentados, de forma mais pormenorizada, por Zylbersztajn (2000). 


\section{Análise empírica}

Nesta seção são apresentadas, primeiramente, a balança comercial do agronegócio brasileiro e a contribuição do Estado de Minas Gerais para o superávit do país, destacando-se os principais produtos e os destinos das exportações do agronegócio mineiro. Posteriormente, a partir dos indicadores de comércio exterior descreve-se a dinâmica da especialização do estado de Minas no período de 1996 a 2006.

\subsubsection{Balança comercial, pauta e destino das exportações}

Os dados da Tabela 1 indicam o extraordinário crescimento das exportações e, como consequiência, dos superávits do agronegócio brasileiro e mineiro no período de 1996 a 2006. No caso do Brasil, podese dividir o período em duas fases, antes e depois de 2000 , ano em que se iniciou o novo ciclo de crescimento das exportações. 
Tabela 1 - Balança comercial do agronegócio, Brasil e Minas Gerais

\begin{tabular}{l|c|c|c|c|c|c|c}
\hline \multirow{2}{*}{ Anos } & \multicolumn{3}{|c|}{ Brasil } & \multicolumn{3}{c|}{ Minas Gerais } & Part. \% \\
\cline { 2 - 8 } & Exportações & Importações & $\begin{array}{c}\text { Saldo } \\
\text { (a) }\end{array}$ & Exportações & Importações & $\begin{array}{c}\text { Saldo } \\
\text { (b) }\end{array}$ & b/a \\
\hline $\mathbf{1 9 9 6}$ & 18,71 & 8,46 & 10,25 & 1,35 & 0,32 & 1,03 & 0,10 \\
$\mathbf{1 9 9 7}$ & 21,00 & 7,74 & 13,26 & 2,29 & 0,30 & 1,99 & 0,15 \\
$\mathbf{1 9 9 8}$ & 19,51 & 7,68 & 11,83 & 2,18 & 0,27 & 1,91 & 0,16 \\
$\mathbf{1 9 9 9}$ & 18,49 & 5,43 & 13,06 & 1,83 & 0,21 & 1,62 & 0,12 \\
$\mathbf{2 0 0 0}$ & 18,17 & 5,49 & 12,68 & 1,67 & 0,19 & 1,48 & 0,12 \\
$\mathbf{2 0 0 1}$ & 21,38 & 4,56 & 16,82 & 1,62 & 0,15 & 1,47 & 0,09 \\
$\mathbf{2 0 0 2}$ & 22,40 & 4,22 & 18,18 & 1,65 & 0,13 & 1,52 & 0,08 \\
$\mathbf{2 0 0 3}$ & 27,97 & 4,48 & 23,49 & 1,98 & 0,14 & 1,84 & 0,08 \\
$\mathbf{2 0 0 4}$ & 35,91 & 4,45 & 31,46 & 2,57 & 0,12 & 2,45 & 0,08 \\
$\mathbf{2 0 0 5}$ & 40,32 & 4,65 & 35,67 & 3,67 & 0,13 & 3,54 & 0,10 \\
$\mathbf{2 0 0 6}$ & 46,22 & 6,04 & 40,18 & 4,21 & 0,19 & 4,02 & 0,10 \\
\hline
\end{tabular}

Fonte de dados: sistema ALICE/SECEX (elaboração própria).

Até 1997, os preços internacionais das principais commodities brasileiras estavam elevados, mas, com o câmbio valorizado, a vantagem de preço era anulada. De 1997 a 1999, observa-se o período de crise para a agricultura brasileira, pois os preços decresceram e o câmbio continuou valorizado, contando ainda com uma taxa de juros real elevada. A partir de 2000, com a desvalorização do câmbio e com a alta de preços no mercado internacional, inicia-se o ciclo de crescimento. As exportações brasileiras, de 2000 a 2006, passaram de US $\$ 18,7$ bilhões para 46,2 US\$ bilhões, o que significa uma taxa anual de crescimento de 19,7\%. Como as importações no período permaneceram por volta de US\$ 5 bilhões, o superávit do setor cresceu a uma taxa anual de $26 \%$, passando de US\$ 12,6 bilhões para a expressiva cifra de US $\$ 40,1$ bilhões. Esse superávit tem contribuído, em parte, para a estabilidade atual da economia, em que se observa a melhoria dos fundamentos macroeconômicos do Brasil. 
Tabela 2 - Principais setores exportadores do agronegócio mineiro, 1996-2006

\begin{tabular}{|c|c|c|c|c|c|c|c|}
\hline \multicolumn{2}{|r|}{ Capítulos } & \multicolumn{2}{|c|}{1996} & \multicolumn{2}{|c|}{2000} & \multicolumn{2}{|c|}{2006} \\
\hline & 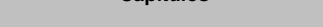 & \multirow{2}{*}{$\begin{array}{c}\begin{array}{c}\text { US\$ } \\
\text { mil Fob }\end{array} \\
9.121\end{array}$} & \multirow{2}{*}{$\begin{array}{c}\text { Part. } \\
(\%) \\
0,67\end{array}$} & \multirow{2}{*}{$\begin{array}{c}\begin{array}{c}\text { US\$ } \\
\text { mil Fob }\end{array} \\
33.666\end{array}$} & \multirow{2}{*}{$\begin{array}{c}\begin{array}{c}\text { Part. } \\
(\%)\end{array} \\
2,00\end{array}$} & \multirow{2}{*}{$\begin{array}{c}\begin{array}{c}\text { US\$ } \\
\text { mil Fob }\end{array} \\
449.788\end{array}$} & \multirow{2}{*}{$\begin{array}{c}\text { Part. } \\
\text { (\%) } \\
10,68\end{array}$} \\
\hline 2 & & & & & & & \\
\hline 4 & Leite e laticínios, ovos de aves, etc. & 663 & 0,05 & 4.412 & 0,26 & 41.576 & 0,98 \\
\hline 9 & Café, chá-mate e especiarias & 898.710 & 66,16 & 996.803 & 59,47 & 2.146 .318 & 50,98 \\
\hline 12 & Sementes e frutas oleaginosas, etc. & 53.311 & 3,92 & 76.559 & 4,56 & 268.250 & 6,37 \\
\hline 17 & Açúcares e produtos de confeitaria & 10.513 & 0,77 & 10.345 & 0,61 & 384.606 & 9,13 \\
\hline \multirow[t]{4}{*}{47} & Pastas de madeira, etc. & 197.144 & 14,51 & 369.352 & 22,03 & 431.562 & 10,25 \\
\hline & Subtotal & 1.169 .461 & 86,09 & 1.491 .137 & 88,93 & 3.722 .100 & 88,39 \\
\hline & Outras & 188.935 & 13,91 & 184.908 & 11,07 & 487.917 & 11,61 \\
\hline & Total & 1.358 .397 & 100 & 1.676 .045 & 100 & 4.210 .017 & 100 \\
\hline
\end{tabular}

Fonte de dados: sistema ALICE/SECEX (elaboração própria).

Os desempenhos da balança comercial dos agronegócios mineiro e brasileiro diferem em razão do grande peso do capítulo 9, café, chámate e especiarias, nas exportações totais do estado de Minas. Isso pode ser constatado ao se analisarem os dados da Tabela 2. Em 1996, os produtos do capítulo 9 eram responsáveis por $66 \%$ das exportações totais, chegando, em 2006, apesar da tendência de queda, à expressiva participação de $51 \%$. Nesse sentido, variações de preço ou de quantidade do produto causam grande impacto nas contas externas do setor.

De 1996 a 1999, quando as exportações do agronegócio brasileiro se encontravam estagnadas, as exportações mineiras tiveram aumento de 61,4\%, em razão, basicamente, da elevação dos preços do café no mercado internacional, expandindo a participação de Minas no superávit brasileiro de $10 \%$ para $16 \%$. A partir de 2000 , quando as exportações brasileiras iniciam o processo de recuperação, as exportações mineiras ficam estagnadas até 2003, em torno de US\$ 1,6 bilhão. Isso ocorreu, em parte, devido ao decréscimo, de 1998 a 2003, de quase 60\% nos preços do capítulo 9 (Gráfico 1), que voltaram a crescer a partir deste ano, em virtude da recuperação dos preços do café, da diversificação da pauta e do aumento nas exportações e, também, da abertura de novos mercados. 
De 2003 a 2006, as exportações do Estado mais que dobraram, passando de

US \$ 1,9 bilhão para US \$ 4,2 bilhões. Conforme dados da Tabela 2, no início desse período, o capítulo 9, café, chá e outras especiarias, e o 47 , pastas de madeira, etc., eram responsáveis por $80,6 \%$ das exportações mineiras; a partir de então, verifica-se um processo de desconcentração das exportações. Em 2006, os capítulos 2 - carnes e miudezas comestíveis, 12 - sementes e frutos oleaginosos, 17 açucares e produtos de confeitaria, que antes tinham participação insignificante, passaram a responder, conjuntamente, por $26 \%$ das exportações totais do Estado.

O ciclo de crescimento das exportações do agronegócio mineiro, iniciado em 2003, além da diversificação da pauta, contou com dois outros fatores, quais sejam, aumento do quantum exportado e alta dos preços no mercado internacional, em uma conjuntura de câmbio real desvalorizado. Os dados do Gráfico 1 indicam que, a partir de 2002, os cinco principais capítulos da pauta de exportação iniciam recuperação dos seus preços no mercado internacional, os quais foram calculados pela divisão da receita de exportação, em dólar americano, pela quantidade exportada, a partir das informações disponibilizadas no banco de dados do sistema Alice/Secex. 


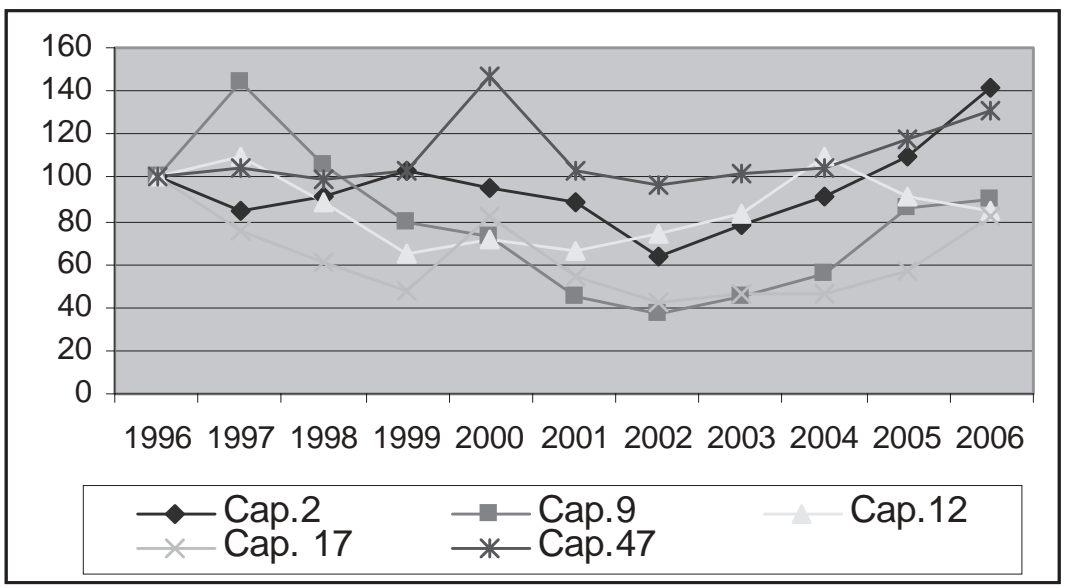

Gráfico 1 - Índices de preços das exportações do agronegócio mineiro dos capítulos 2, 9, 12, 17 e 47, no período de 1996 a 2006

Fonte de dados: sistema ALICE/SECEX (elaboração própria. Base 100 = 1996).

O Gráfico 2 demonstra que os produtos mais tradicionais da pauta de exportação do Estado, como os capítulos 9 e 47, entre 1996 e 2000, apresentaram pequeno aumento no quantum exportado. A partir de então, observa-se crescimento mais vigoroso, chegando a exportar, ao final do período, respectivamente $200 \%$ e $100 \%$ mais que em 1996. Com relação ao capítulo 12, sementes e frutos oleaginosos, a primeira fase de crescimento do quantum exportado ocorreu em 1998, com acréscimo de $100 \%$ nas exportações. Desde então até 2001, as exportações estabilizaram-se e, a partir de 2002, houve vigoroso aumento, apresentando, em 2006, um crescimento de $400 \%$ em relação ao início do período. 


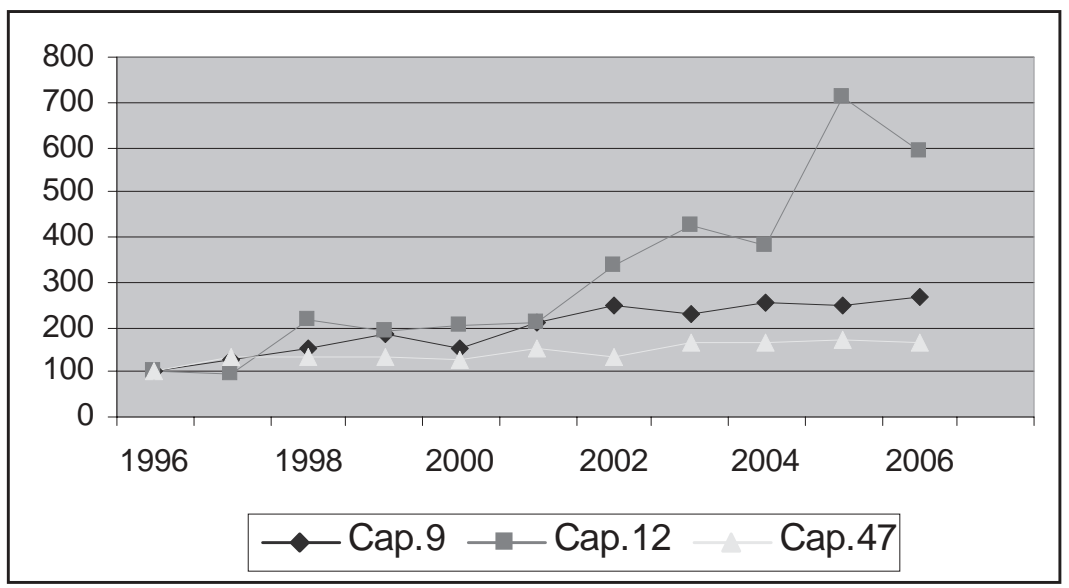

Gráfico 2 - Índices de quantum das exportações do agronegócio mineiro dos capítulos 9, 12 e 47, no período de 1996 a 2006

Fonte de dados: sistema ALICE/SECEX (elaboração própria. Base 100 = 1996).

No Gráfico 3, observa-se que os capítulos 2, carnes e miudezas comestíveis, e 17, açúcares e produtos de confeitaria, contavam, em 1996, com participações insignificantes, visto que respondiam por menos de $1 \%$ das exportações totais do Estado. O capítulo 2 inicia o ciclo de crescimento em 2000 e chega, ao final do período, ao volume de exportações $3.000 \%$ superior ao verificado em 1996. Já o capítulo 17, apesar de ter crescido na fase anterior, inicia também, em 2000, um crescimento contínuo, chegando ao final do período com volume de exportações de 4.200\% superior ao de 1996. 


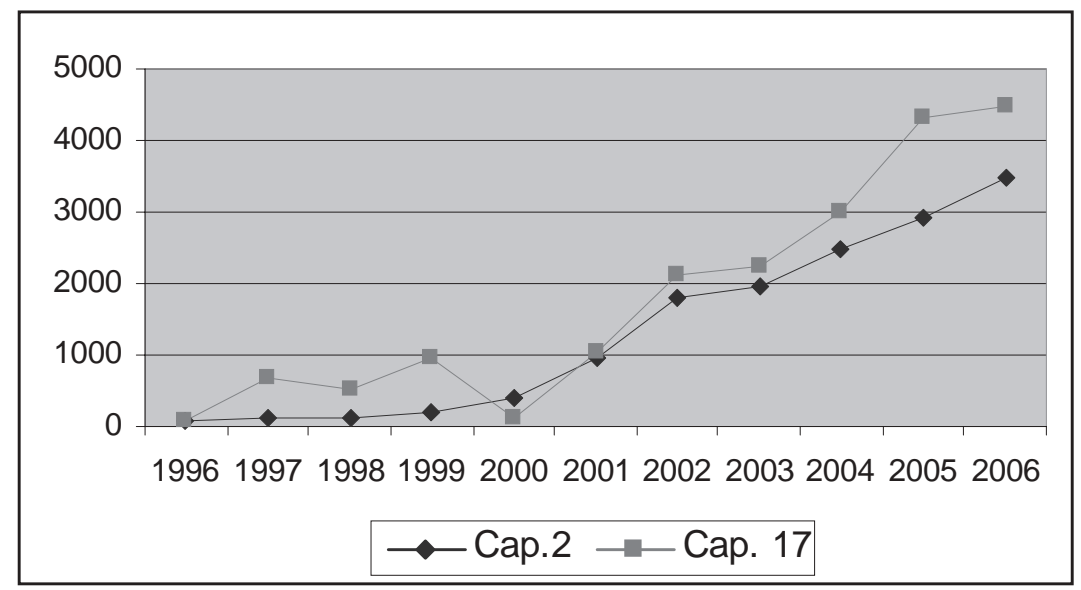

Gráfico 3 - Índices de quantum das exportações do agronegócio mineiro dos capítulos 2 e 17, no período de 1996 a 2006

Fonte de dados: sistema ALICE/SECEX (elaboração própria. Base 100 = 1996).

Na Tabela 3, que descreve o destino das exportações do agronegócio mineiro por regiões e blocos econômicos, verifica-se que as receitas das exportações, no período de 2000 a 2006, com exceção do Mercosul, aumentaram em todas as regiões e blocos econômicos. Cabe destacar o crescimento de $262,1 \%$ nas receitas dos "novos mercados", o qual superou o verificado nos "mercados tradicionais", de $114,1 \%$, e "nos demais mercados", de 154,7\%. Esse comportamento resultou na desconcentração dos destinos das exportações do agronegócio mineiro. É importante destacar que $31 \%$ das exportações, em 2006, se destinaram a "novos mercados, enquanto em 2000 essa parcela foi de $21,5 \%$. Nos mercados tradicionais, essa participação caiu para 55,8\%, enquanto em 2000 era de $65,5 \%$. A diversificação do mercado tem significado importante para o setor, na medida em que reduz a dependência de mercados como União Européia e Nafta, que, apesar de participarem de fóruns internacionais de liberalização comerciais, ainda insistem em manter, principalmente para o setor agrícola, políticas comerciais protecionistas e altas barreiras tarifárias. No entanto, o que se verifica é que grande parte do sucesso do agronegócio mineiro se deve à estratégia de ampliar o mercado; nesse 
sentido, vale ressaltar o crescimento da participação dos países da África, Europa Oriental e Oriente Médio nas exportações do setor.

Tabela 3 - Destino das exportações do agronegócio mineiro por regiões e blocos econômicos - 2000 e 2006 (US\$)

\begin{tabular}{|c|c|c|c|c|c|}
\hline & 2006 & Part. \% & 2000 & Part. \% & Var.\% \\
\hline Mercados tradicionais & 2.349.057.033 & 55,8 & 1.097.331.349 & 65,5 & 114,1 \\
\hline Nafta & 485.032 .220 & 11,5 & 216.049 .365 & 12,9 & 124,5 \\
\hline União Européia & 1.732 .283 .810 & 41,1 & 832.274 .457 & 49,7 & 108,1 \\
\hline Mercosul & 19.922 .916 & 0,5 & 20.025 .835 & 1,2 & $-0,5$ \\
\hline Aladi (excl. Mercosul) & 111.818 .087 & 2,7 & 28.981 .692 & 1,7 & 285,8 \\
\hline Novos mercados & 1.304.668.549 & 31,0 & 360.341 .450 & 21,5 & 262,1 \\
\hline Ásia (excl.Oriente Médio) & 761.595 .681 & 18,1 & 320.099 .780 & 19,1 & 137,9 \\
\hline África (excl. Oriente Médio) & 195.028 .472 & 4,6 & 7.033 .099 & 0,4 & 2673,0 \\
\hline Europa Oriental & 206.357 .153 & 4,9 & 4.805 .244 & 0,3 & 4194,4 \\
\hline Oriente Médio & 141.687 .243 & 3,4 & 28.403 .327 & 1,7 & 398,8 \\
\hline Demais países & 556.291 .418 & 13,2 & 218.372.201 & 13,0 & 154,7 \\
\hline TOTAL & 4.210.017.000 & 100 & 1.676 .045 .000 & 100 & 151,2 \\
\hline
\end{tabular}

Fonte de dados: sistema ALICE/SECEX (elaboração própria).

\subsection{Indicadores de comércio exterior}

Os indicadores da vantagem comparativa revelada (VCR), descritos na Tabela 4, demonstram a dinâmica da especialização e competitividade do agronegócio mineiro, desagregado em 34 capítulos, no período de 1996 a 2006. Como foi apresentado na metodologia, se o indicador for superior à unidade, isso significa que a participação das exportações do Estado nas exportações do país, em dado produto, será superior a essa mesma relação nas exportações totais do agronegócio. Para facilitar a análise da Tabela 4, os indicadores maiores que a unidade estão descritos em negrito. 
O estado de Minas Gerais apresenta vantagem comparativa nos capítulos 9, café, chá- mate e especiarias, e 47, pastas de madeira etc., em todo o período. O capítulo 9, em 1996, com indicador de 6,77, iniciou a consolidação das vantagens, chegando em 2004 com o expressivo valor de 9,41. Após esse ano, o indicador passa por uma perda, terminando o período com o índice de 7,54. No capítulo 47, de 1996 a 2001, o indicador passa de 2,72 para 3,28. Após esse período, observa-se decréscimo do indicador, que chega em 2006 com o valor de 1,91. 
Tabela 4 - Vantagem comparativa revelada (VCR) do agronegócio mineiro, desagregado por capítulos, 1996 a 2006



Fonte de dados: sistema ALICE/SECEX (elaboração própria). 
Podem-se destacar os capítulos 1, animais vivos; 4, leite e laticínios; 6 , plantas vivas e produtos de floricultura; 7 , produtos hortícolas; 11, produtos da indústria de moagem; 18, cacau e suas preparações; 19, preparações à base de cereais; e, finalmente, 52, algodão, que não apresentaram posição consolidada na especialização do comércio internacional, visto que houve oscilações, com períodos de competitividade e de desvantagens competitivas. O capítulo 4, leite e laticínios, por exemplo, a partir de 1999, apresenta tendência de crescimento da vantagem competitiva, chegando, em 2006, a um índice de 2,39. Entretanto, como o setor tem pequena inserção no mercado internacional, com participação abaixo de um ponto porcentual na pauta de exportações (Tabela 2), esse crescimento resultou em pequeno impacto nas contas externas do Estado.

Cabe, entretanto, destacar os setores que apresentaram desvantagem competitiva em todo o período, mas que, gradativamente, reduziram essas desvantagens. Podem-se destacar, entre outros, três importantes capítulos que, em 2006, responderam, conjuntamente, por cerca de $25 \%$ das exportações mineiras, quais sejam, 2, carnes e miudezas comestíveis; 12, sementes e frutos oleaginosos; e 17, açúcares e produtos de confeitaria. O capítulo 2, por exemplo, entre 2000 e 2006, reduziu consideravelmente as suas desvantagens, em uma conjuntura em que o país se tornou o maior exportador do mundo no setor de carnes, cujo índice passou de 0,23 para 0,67. Isso significa que o Estado conseguiu reverter suas desvantagens, em um ambiente de aumento de competitividade do setor no país, resultando, no período, em crescimento de US\$ 415 milhões nas exportações.

O agronegócio mineiro, considerando-se todos os produtos, apresentou, em todo o período, desvantagem competitiva; entretanto, essa desvantagem também vem sendo revertida, visto que o índice iniciou o período com 0,60 e terminou com 0,80. Nesse sentido, vale a pena identificar o fator determinante desse aumento. Conforme a descrição da metodologia, no caso do estado de Minas Gerais, o índice retrata a participação das exportações do agronegócio mineiro no total das 
exportações do setor no país, em relação à exportação do Estado nas exportações totais do Brasil. O crescimento do indicador se deve a dois fatores; primeiro, ao decréscimo na participação estadual nas exportações totais do país, de $12,1 \%$ para $11,3 \%$; e, principalmente, ao aumento da participação das exportações de Minas no total das exportações do agronegócio brasileiro, de 7,2\% para 9,1\%. Esse aumento na participação é bastante expressivo, tendo em vista que o agronegócio brasileiro, nesta última década, obteve desempenho notável, o que coloca o país entre as nações mais competitivas do mundo e demonstra o ganho de eficiência do setor em Minas Gerais.

A evolução da especialização do agronegócio mineiro, medida pelos indicadores de contribuição ao saldo comercial (ICSC), da Tabela 5, aponta um comportamento semelhante ao verificado por meio da vantagem comparativa revelada (VCR), como visto na Tabela 4. Isso porque, novamente, destacam-se os capítulos 9, café, chá, mate e especiarias, e 47, pastas de madeira, com as maiores contribuições para o saldo comercial. Essa contribuição, no decorrer do período, decresceu em razão da diversificação das exportações do Estado, com o aumento da contribuição dos capítulos 2, carnes e miudezas; 12 , sementes e frutos oleaginosos; 16, preparações de carne, e 41, peles e couros. 
Tabela 5 - Índice de contribuição ao saldo comercial (ICSC) do agronegócio mineiro, desagregado por capítulos, 1996 a 2006

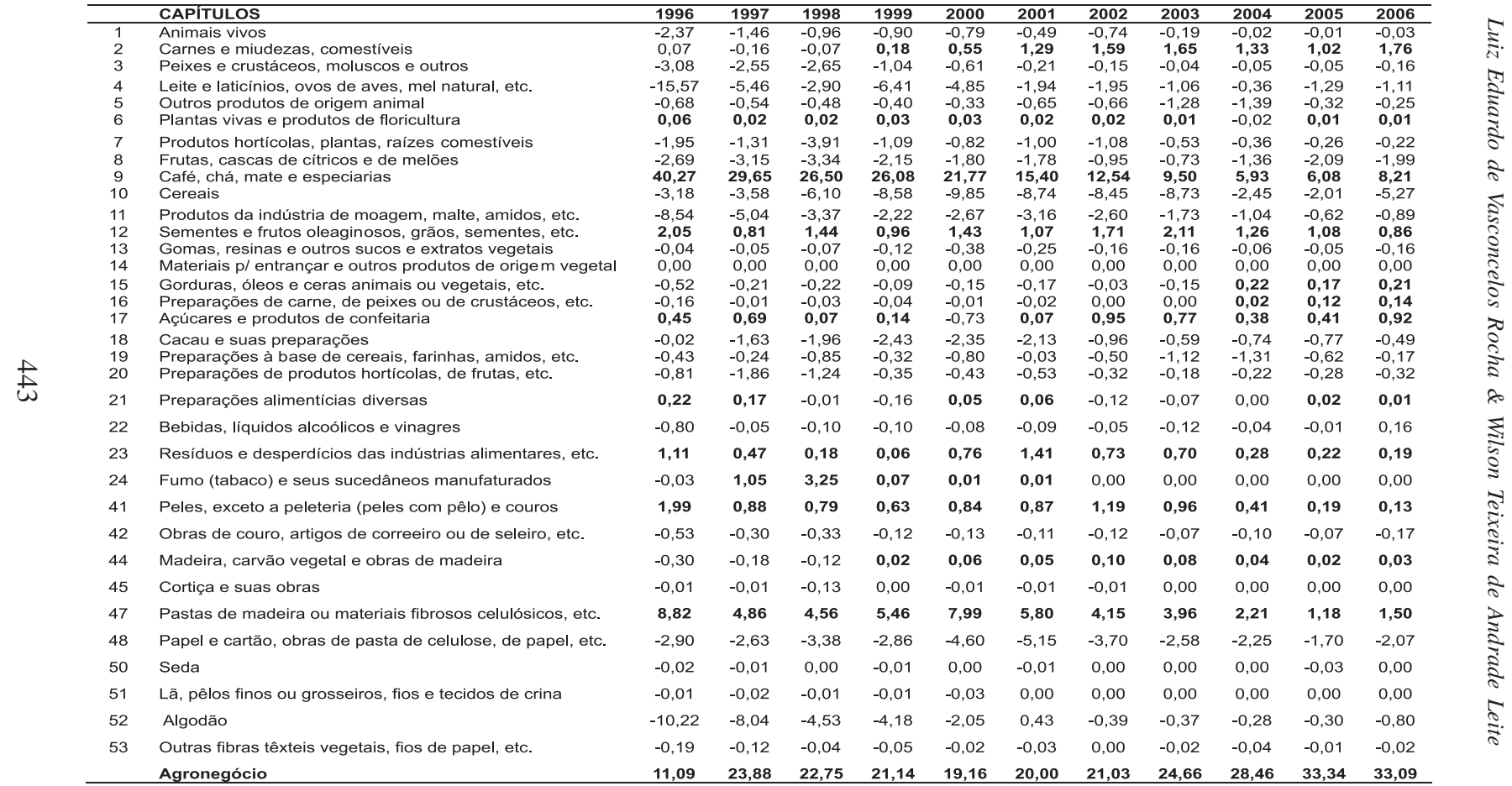

Fonte de dados: sistema ALICE/SECEX (elaboração própria). 
Esse aumento de participação resultou no decréscimo dos indicadores de contribuição dos capítulos 9, café, chá, mate e especiarias; e 47, pastas de madeira, que passaram, entre 1996 e 2006, respectivamente, de 40,2 para 8,2 e de 8,8 para 1,5. Cabe ressaltar o comportamento do índice de contribuição do agronegócio nas exportações do Estado, que, no período, passou de 11,1 para 33,1. É importante destacar que esse aumento na participação se deu pela diversificação das exportações, o que minimizou o efeito de crises pontuais em países ou produtos específicos, como ocorreu com o decréscimo dos preços do café, entre 1997 e 2002, na economia do setor e, conseqüentemente, do Estado.

A análise da evolução da estrutura do comércio exterior e das vantagens competitivas pode ser feita pela identificação dos pontos fortes do setor, que, segundo o critério de Gutman e Viotti (1996), são os que apresentam, simultaneamente, taxa de cobertura maior que a unidade e vantagem comparativa revelada. Os produtos com desvantagem comparativa revelada e, simultaneamente, taxa de cobertura inferior à unidade são considerados pontos fracos. No caso em que se observam vantagem comparativa e taxa de cobertura inferior à unidade ou vive-versa, o produto é considerado ponto neutro. De acordo com as Tabelas 4 e 6, os capítulos foram identificados como "forte, fraco e neutro" e estão representados na Tabela 7.

Conforme dados da Tabela 7, a diversificação do agronegócio mineiro inicia-se a partir de 1999, com o aumento de capítulos identificados como "ponto forte" na economia. Antes desse período, apenas os capítulos 9, café, chá-mate especiarias; 47, pasta de madeira e, no ano de 1996, e 6, plantas vivas, eram considerados "pontos fortes". Após 1999, os capítulos 1, animais vivos; 4, leite e laticínios; 18, cacau e suas preparações; 19 , preparações à base de cereais; 41 peles e couros; e, finalmente, 52, algodão, apresentam, em pelo menos um ano, a identificação como "ponto forte". O agronegócio mineiro, no estágio de crescimento do setor no país, manteve, na última década, a competitividade dos setores tradicionais, como café e madeira, e ainda diversificou a sua produção para outros setores com maior valor agregado. O indicador 
de competitividade para o agronegócio mineiro demonstrou-se "neutro", isso porque, como pode ser observado na Tabela 4, o setor apresenta desvantagem competitiva revelada, que vem sendo gradativamente revertida. Se mantiver essa tendência, sem sombra de dúvidas, em futuro próximo o setor será qualificado como "ponto forte" da economia, tendo em vista a grande contribuição para o saldo comercial de Minas Gerais. 
Tabela 6 - Taxa de cobertura do agronegócio mineiro, desagregado por capítulos, 1996 a 2006

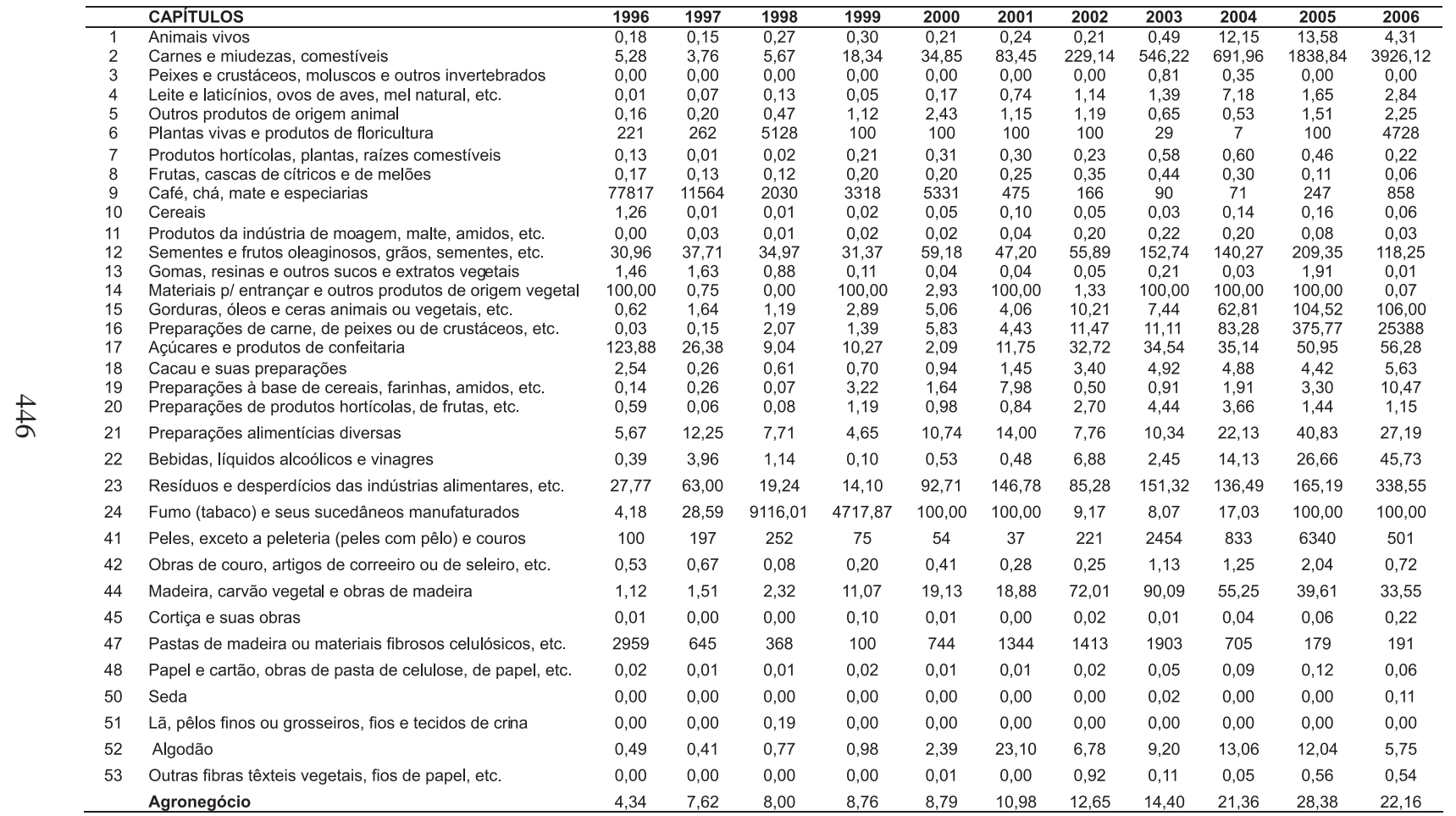

Fonte de dados: sistema ALICE/SECEX (elaboração própria). 
Tabela 7 - "Pontos fortes" e "pontos neutros" do agronegócio mineiro, desagregado por capítulos, 1996 a 2006

\begin{tabular}{|c|c|c|c|c|c|c|c|c|c|c|c|c|}
\hline & CAPITULOS & 1996 & 1997 & 1998 & 1999 & 2000 & 2001 & 2002 & 2003 & 2004 & 2005 & 2006 \\
\hline 1 & Animais vivos & Neutro & Neutro & Neutro & $\mathrm{Neu}$ & Neutro & Neutro & Neutro & Fraco & Forte & Neutro & Neutro \\
\hline 2 & Carnes e miudezas, comestiveis & Neutro & Neutro & Neutro & Neutro & & & & Neutro & Neutro & Neutro & Neutro \\
\hline 3 & Peixes e crustáceos, moluscos e outros invertebra & Fraco & Fraco & Fraco & Fraco & Fraco & & Fraco & & & & Fraco \\
\hline 4 & Leite e laticínios, ovos de aves, mel natural, etc. & Fraco & Neutro & Fraco & Neutro & Neutro & Neutro & Forte & Fo & & & \\
\hline 5 & Outros produtos de origem animal & Fraco & & & & & & & & & & \\
\hline 6 & thas vivas e pro & Forte & Neutro & Neutro & Forte & Forte & Forte & Forte & Fol & & & Neutro \\
\hline 7 & Produtos horticolas, plantas, raizes comestiveis & Neutro & Fraco & Fraco & Fraco & Fraco & Neutro & Fraco & Neutro & Neutro & & Fraco \\
\hline 8 & Frutas & Fraco & Fraco & Fraco & Fraco & Fraco & Fraco & Fraco & Frac & Fraco & & Fraco \\
\hline $\begin{array}{l}0 \\
9\end{array}$ & Café, ch & & & & & & & & & & & Forte \\
\hline 10 & Cereais & Forte & Fraco & Fraco & Fraco & Neutro & Fraco & Fraco & Fraco & Fraco & Fraco & Fraco \\
\hline 11 & Produtos da indústria de moagem, malte, amidos, etc. & Fraco & Fraco & Fraco & Fraco & Fraco & Fraco & Neutro & Neutro & Neutro & Fraco & Fraco \\
\hline 12 & Sementes e frutos oleaginosos, grãos, sementes, etc. & Neutro & Neutro & Neutro & Neutro & Neutro & Neutro & Neutro & Neutro & Neutro & Neutro & Neutro \\
\hline 13 & Gomas, resinas e outros sucos e extratos vegetais & Neutro & Neutro & Fraco & Fraco & Fraco & Neutro & Fraco & Fraco & Fraco & Fraco & Fraco \\
\hline 14 & Materiais $p /$ entrançar e outros produtos de origem vegetal & Neutro & Fraco & Neutro & Neutro & Neutro & Neutro & Neutro & Neutro & Neutro & Neutro & Fraco \\
\hline 15 & Gorduras, óleos e ceras animais ou vegetais, etc. & Fraco & Neutro & Neutro & Neutro & Neutro & Neutro & Neutro & Neutro & Neutro & Neutro & Neutro \\
\hline 16 & Preparaçōes de carne, de peixes ou de crustáceos, etc. & Fraco & Fraco & Neutro & Neutro & Neutro & Neutro & Neutro & Neutro & Neutro & Neutro & Neutro \\
\hline 17 & Açúcares e produtos de confeitaria & Neutro & Neutro & Neutro & Neutro & Neutro & Neutro & Neutro & Neutro & Neutro & Neutro & Neutro \\
\hline 18 & Cacau e suas preparações & Neutro & Fraco & Fraco & Fraco & Neutro & Forte & Forte & Forte & Forte & Forte & Forte \\
\hline 19 & Preparações à base de cereais, farinhas, amidos, etc. & Fraco & Fraco & Fraco & Forte & Forte & Forte & Fraco & Forte & Forte & Forte & Forte \\
\hline 20 & Preparações de produtos hortícolas, de frutas, etc. & Fraco & Fraco & Fraco & Neutro & Neutro & Fraco & Neutro & Neutro & Neutro & Neutro & Neutro \\
\hline 21 & Preparações alimentícias diversas & Neutro & Neutro & Neutro & Neutro & Neutro & Neutro & Neutro & Neutro & Neutro & Neutro & Neutro \\
\hline 22 & Bebidas, líquidos alcoólicos e vinagres & Fraco & Neutro & Fraco & Neutro & Fraco & Fraco & Neutro & Neutro & Neutro & Neutro & Neutro \\
\hline 23 & Resíduos e desperdícios das indústrias alimentares, etc. & Neutro & Neutro & Neutro & Neutro & Neutro & Neutro & Neutro & Neutro & Neutro & Neutro & Neutro \\
\hline 24 & Fumo (tabaco) e seus sucedâneos manufaturados & Neutro & Neutro & Neutro & Neutro & Neutro & Neutro & Neutro & Neutro & Neutro & Neutro & Neutro \\
\hline 41 & Peles, exceto a peleteria (peles com pêlo) e couros & Neutro & Neutro & Neutro & Neutro & Neutro & Forte & Forte & Forte & Neutro & Neutro & Neutro \\
\hline 42 & Obras de couro, artigos de correeiro ou de seleiro, etc. & Fraco & Fraco & Fraco & Fraco & Fraco & Fraco & Fraco & Neutro & Neutro & Neutro & Fraco \\
\hline 44 & Madeira, carvão vegetal e obras de madeira & Neutro & Neutro & Neutro & Neutro & Neutro & Neutro & Neutro & Neutro & Neutro & Neutro & Neutro \\
\hline 45 & Cortiça e suas obras & Fraco & Fraco & Fraco & Fraco & Fraco & Fraco & Fraco & Fraco & Fraco & Fraco & Fraco \\
\hline 47 & Pastas de madeira ou materiais fibrosos celulósicos, etc. & Forte & Forte & Forte & Forte & Forte & Forte & Forte & Forte & Forte & Forte & Forte \\
\hline 48 & Papel e cartão, obras de pasta de celulose, de papel, etc. & Fraco & Fraco & Fraco & Fraco & Fraco & Fraco & Fraco & Fraco & Fraco & Fraco & Fraco \\
\hline 50 & Seda & Fraco & Fraco & Fraco & Fraco & Fraco & Fraco & Fraco & Fraco & Fraco & Fraco & Fraco \\
\hline 51 & Lã, pêlos finos ou grosseiros, fios e tecidos de crina & Fraco & Fraco & Fraco & Fraco & Fraco & Fraco & Fraco & Fraco & Fraco & Fraco & Fraco \\
\hline 52 & Algodão & Neutro & Neutro & Neutro & Forte & Forte & Forte & Forte & Forte & Forte & Neutro & Forte \\
\hline 53 & Outras fibras têx & co & Fraco & Fraco & Fraco & raco & Fraco & raco & Fraco & Fraco & Fraco & Fraco \\
\hline & Agronegócio & Neutro & Neutro & Neutro & Neutro & Neutro & Neutro & Neutro & Neutro & Neutro & Neutro & Neutro \\
\hline
\end{tabular}

Fonte de dados: sistema ALICE/SECEX (elaboração própria) 


\section{Conclusões}

O atual estágio de desenvolvimento do agronegócio brasileiro, que coloca o país entre as nações mais competitivas do mundo na produção de commodities agroindustriais, teve o seu momento de inflexão a partir de 2000, com a desvalorização do real e com o aumento da demanda no mercado internacional.

Dentro desse contexto, o agronegócio mineiro aumentou sua vantagem competitiva no país, diversificando a pauta e o destino de suas exportações. Cabe destacar o crescimento nas receitas para os "novos mercados", que superou o verificado nos "mercados tradicionais". Essa diversificação tem significado importante para o estado de Minas, na medida em que diminui a dependência de regiões como União Européia e Nafta, que, apesar de participarem de fóruns internacionais de liberalização comerciais, ainda insistem em manter, principalmente para o setor agrícola, políticas comerciais protecionistas e altas barreiras tarifárias.

A análise da evolução da estrutura do comércio exterior e das vantagens competitivas, com base nos indicadores de fluxos comerciais, evidenciou também a diversificação do agronegócio mineiro, com o aumento de capítulos identificados como "ponto forte" na economia. No ciclo de crescimento do setor no país, o agronegócio mineiro manteve, na última década, a competitividade dos setores tradicionais e ainda diversificou a sua produção para outros setores com maior valor agregado. Entretanto, o indicador de competitividade para o agronegócio mineiro foi "neutro", isso porque o setor apresentou desvantagem competitiva revelada, que vem sendo gradativamente revertida. Se mantiver essa tendência, sem sombra de dúvidas, em futuro próximo o setor será qualificado como "ponto forte" da economia, tendo em vista a grande contribuição para o saldo comercial mineiro.

Por fim, cabe ressaltar que a continuidade do processo de desenvolvimento e da competitividade do agronegócio mineiro, descrito neste trabalho, depende de conjuntura macroeconômica que garanta câmbio competitivo 
e taxas de juros reais que possam viabilizar novos investimentos produtivos e, também, a melhoria da infra-estrutura e da logística de suporte ao setor. Neste último aspecto, o governo do Estado tem papel importante na promoção da melhoria das condições das rodovias e ferrovias, garantindo o escoamento da produção a custos competitivos, bem como no investimento em biotecnologia, o qual pode ser decisivo, em futuro próximo, na determinação das vantagens comparativas no mercado internacional.

\section{Referências}

BACHA, Carlos José Caetano. Economia e política agrícola no Brasil. São Paulo: Atlas, 2004.

BALASSA, Bela. Trade liberalization and revealed comparative advantage. Washington: World Bank, 1965.

FERNANDES, Cândido Luiz de Lima; VIEIRA, João Eustáquio Ribeiro. Especialização e competitividade de Minas Gerais no mercado internacional: um estudo de indicadores de comércio exterior no período de 1992 a 1999. In: SEMINÁRIO SOBRE ECONOMIA MINEIRA, 9., 2000, Diamantina. Anais... Belo Horizonte: CEDEPLAR/UFMG, 1998.

GUTMAN, G. E.; MIOTTI, L. E. Exportaciones agroindustriales de América Latina y Caribe: especialización, competitividad y oportunidades comerciales em los mercado de la OCDE apud HIDALGO, Álvaro Barrantes. Especialização e competitividade do Nordeste no mercado internacional. Revista Econômica do Nordeste, Fortaleza, v. 29, p. 491-515, jul.1998. Número especial.

HIDALGO, Álvaro Barrantes. Especialização e competitividade do Nordeste no mercado internacional. Revista Econômica do Nordeste, Fortaleza, v. 29, p. 491-515, jul.1998. Número especial. 
JANK, Marcos Sawaya; NASSAR, André Meloni; TACHINARDI, Maria Helena. Agronegócio e comércio exterior. Revista USP, São Paulo, n. 64, p.14-27, fev. 2005.

LAFAY, G. Mesure des avantages comparatifs reveles. Économie perspective intenationale, Paris, n. 41, 1990.

MAIA, Sinézio Fernandes. Transformações na estrutura produtiva de Estado do Paraná na década de 90: análise por vantagem comparativa. In: MAIA, Sinézio; MEDEIROS, Fernandes; NATALINO, Henrique (Orgs.). Transformações recentes da economia paranaense. Recife: Editora Universitária da UFPE, 2005. 156 p.

SECEX/MICT. Secretaria de Comércio Exterior do Ministério da Indústria, Comércio e Turismo. Disponível através do sistema ALICE (Análise das Informações de Comércio Exterior): <http:www.aliceweb.gov.br>. Acesso em: entre 15 a 10 fev. 2007.

ZYLBERSZTAJN, D. Conceitos gerais, evolução e apresentação do sistema agroindustrial. In: ZYLBERSZTAJN, D.; NEVES, M. F. (Orgs.). Economia e gestão dos negócios agroalimentares. São Paulo: Pioneira, 2000. p.1-21. 


\begin{abstract}
The present development in the Brazilian Agro-business, which regards this country as one the most competitive nations in terms of agro industrial commodities, had its best expansion moments from 2006 on especially with the fall of Real currency and due to an increasingly demand in the international market. The aim of this article is to analyze the specialization and competitiveness of the agro-industry in the state of Minas Gerais and its contribution to the increase in the Brazilian exportations. To that end, indexes based on commercial flux will be used so that we are able to identify the trends in the international marked in terms of specializations. The analyses of the international business structure and the profitable competitiveness have shown the diversity of Minas Gerais agro-business, started off in 1999, with the increase in the socalled 'strong spots' of economy. Not only did Minas Gerais State manage to keep the competitiveness in traditional sectors such as coffee and timber industry but it also diversified its production to other potential sectors of its economy. However, the competitiveness index has come as 'neutral' due to low competition, a fact that has been gradually overcome. Should such tendency maintain, without a shadow of doubt, the agro-business will soon be considered as a strong spot in the Mineira economy.
\end{abstract}

Key words: competitive advantage, specialization, agro-business. 
REVISTA DE ECONOMIA E AGRONEGÓCIO, VOL.5, $N^{o} 3$ 